Zhanyong Guo*, Fachuang Li, Guang Su, Demei Zhai and Chenhui Liu

\title{
Microwave drying of nickel-containing residue: dielectric properties, kinetics, and energy aspects
}

https://doi.org/10.1515/gps-2019-0051

Received March 27, 2019; accepted May 28, 2019.

\begin{abstract}
Nickel-containing residue (NCR) is a hazardous solid waste from battery production lines. Recently, the interest in recovering valuable metals from NCR has increased because sustainable utilization of resources is more and more valued. Drying is a key part of the recovery process. In this study, we measured the dielectric properties of the NCR for different moisture contents and temperatures using the cavity perturbation method at $2.45 \mathrm{GHz}$. The microwave absorption characteristics of NCR had a positive correlation with the moisture content, while it was less efficient in the $20-180^{\circ} \mathrm{C}$ temperature range. Then found that the microwave drying data at different microwave powers (400-700 W) and for different sample weights (60-120 g) have a better fit with the Midilli-Kucuk model. The activation energy (Ea) was received as $9.76 \mathrm{~W} / \mathrm{g}$ using an exponential expression based on the Arrhenius equation. Finally, the energy consumption reduce $110 \mathrm{~W} \cdot \mathrm{h} / \mathrm{kg}$ than that of drying with a single microwave power by optimizing the microwave drying process.
\end{abstract}

Keywords: nickel-containing residue; microwave drying; dielectric properties

\section{Introduction}

In the battery production process, some components like the battery case and chip must be nickel plated $[1,2]$. Therefore, a large number of electroplating wastewater is produced and is usually treated by chemical precipitation to meet the discharge standards $[3,4]$. This then creates nickel-containing residue, a cheap secondary resource $[5,6]$.

\footnotetext{
* Corresponding author: Zhanyong Guo, School of Materials Science and Engineering, Henan Institute of Technology, Xinxiang, Henan, China, e-mail: guozhanyong123@126.com, Tel: +86-0373-3691137

Fachuang Li, Guang Su, Demei Zhai, School of Materials Science and Engineering, Henan Institute of Technology, Xinxiang, Henan, China Chenhui Liu, Key Laboratory of Unconventional Metallurgy, Ministry of Education, Kunming, Yunnan, China
}

If not handled properly, secondary pollution will occur and have a negative impact on the environment and on human health. Currently, common treatment methods include separation and recovery of the heavy metals $[7,8]$, solidification treatment $[9,10]$, and high-temperature incineration [11]. However, because of the high water content and the stickiness, it becomes crucial to efficiently yet economically dry the NCR before recycling, solidification, or incineration.

Compared to the conventional low-efficiency, timeconsuming, and energy-consuming drying technologies [12], such as fluidized bed drying [13], rotary kiln drying [14] as well as other conventional drying methods [15,16], the efficiency of microwave drying is more than twice that of conventional drying methods [17,18]. The water molecules in the material make most of the sample have an excellent absorbency for the electromagnetic wave. During microwave heating, heat and water vapor travel in the same direction which causes a high drying efficiency [19-22].

As a sticky material the NCR tends to absorb and retain a large amount of water, which makes a great obstacle for the press filtration process, and there is still a high moisture content in the material after dehydration. Furthermore, in the conventional drying process, the viscosity of the material maintains a high internal cohesion, thus delaying the evaporation of water molecules. From our earlier results drying a $\mathrm{CuCl}$ residue, need more than $90 \mathrm{~min}$ to reduce the moisture content of the residue from $36 \%$ to about $4 \%$ [23]. By contrast, under a microwave power of $550 \mathrm{~W}$, the same effect can be achieved in just about $10 \mathrm{~min}$ [24].

In this study, the dielectric properties is measured by cavity perturbation method, microwave drying kinetics is collected using eight thin layer drying models, and energy consumption during microwave drying process is optimized using response surface methodology (RSM).

\section{Materials and methods}

\subsection{Raw materials}

The nickel-containing residue (NCR) was supplied by a battery manufacturer in Henan Province, China. The 
received samples contained $45.8 \%$ water and were very sticky.

After drying, the sample was analyzed chemically and by X-ray powder diffraction (XRD). The results of the chemical composition and the XRD pattern are shown in Table 1 and Figure 1.

As shown in Table 1, there is a variety of metallic elements in the NCR and nickel content is found to be above $8 \%$. It is practically important to effectively separate the impurities and recovery of nickel.

From Figure 1, the material composition is relatively complex, with a main phase of $\mathrm{CaCO}_{3}$. $\mathrm{Mg}$ mainly exists in the $\mathrm{MgSiO}_{3}$ form while Ni mainly exists in the $\mathrm{NiO}$ form. Low amounts of $\mathrm{NiCO}_{3}$ and $\mathrm{Ni}(\mathrm{OH})_{2} \cdot 2\left(\mathrm{H}_{2} \mathrm{O}\right)$ are also present whereas Fe mainly exists in the $\mathrm{FeSiO}_{3}$ form.

\subsection{Experimental devices}

\subsubsection{Permittivity measurement system}

A permittivity measurement system based on microwave cavity perturbation method was used to measure the dielectric parameters of the NCR. The testing equipment has been widely used for the measurement of dielectric properties of materials [25-27]. A schematic of the system is shown in Figure 2.

The device consists of a vector network analyser, a waveguide-coax transition, a directional coupler, an

Table 1: Chemical composition of the NCR residue.

\begin{tabular}{ccccccccc}
\hline Composition & 0 & $\mathrm{Ca}$ & $\mathrm{Mg}$ & $\mathrm{C}$ & $\mathrm{Ni}$ & $\mathrm{Fe}$ & $\mathrm{Si}$ & $\mathrm{Cd}$ \\
\hline Content (\%) & 53.42 & 14.09 & 8.67 & 8.30 & 8.02 & 4.64 & 1.57 & 0.71 \\
\hline
\end{tabular}

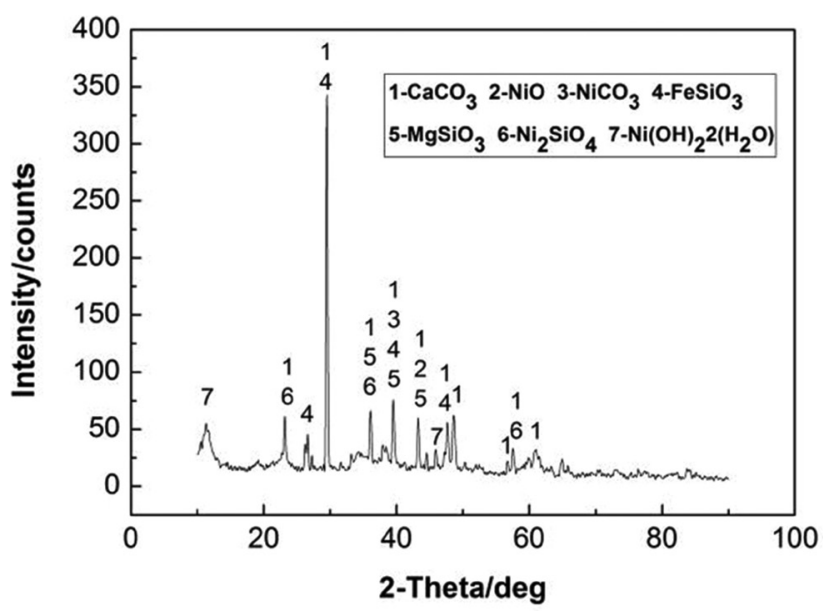

Figure 1: XRD pattern of the raw material. electromagnetic induction heater, a water re-circulator, a gas lift, and a cavity resonator. The test control unit is connected to a computer via a USB data cable and software calculates the dielectric parameters. The system accuracy has been demonstrated in our preliminary work which was estimated to be $3 \%$ in the dielectric constant and 10\% in the loss factor during the tests [27].

During the experiments, the test sample was placed into the heater of the permittivity measurement system with a small quartz tube. When the NCR was heated to a pre-set temperature and subsequently lifted into the cavity resonator via the gas lift, the computer rapidly calculated the dielectric parameters using the test-cavity perturbation theory. After the test, the quartz tube was lowered into the heater and heated to a higher pre-set temperature to measure the permittivity at different temperatures.

\subsubsection{Microwave oven for the drying experiments}

A microwave reactor with a power of $3 \mathrm{~kW}$ and a frequency of $2.450 \mathrm{GHz}$ was used for the drying experiments. Its schematic is presented in Figure 3. The microwave drying system consists of a weightlessness measurement system, a temperature control unit with a thermo-element, two magnetrons, a multimode cavity, a quartz glass container, and a date acquisition computer. A thermocouple pyrometer was inserted into the centre of the sample to measure the heating temperature.

During the microwave drying experiments, a certain amount (120 g, $100 \mathrm{~g}, 80 \mathrm{~g}$, or $60 \mathrm{~g}$ ) of sample with a moisture content of $45.8 \%$ (d.b.) and shaped into a $10 \mathrm{~mm}$ thin layer was loaded into a quartz glass

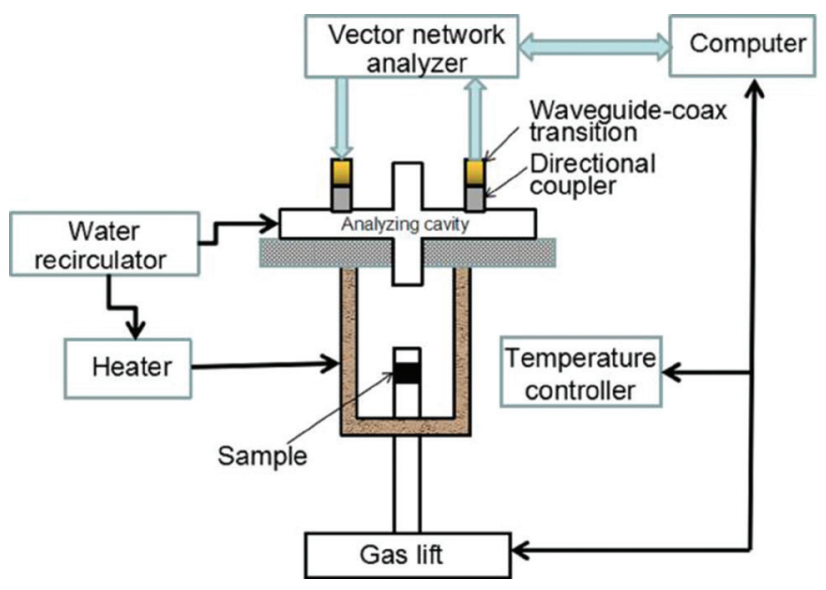

Figure 2: Schematics of the permittivity measurement system. 


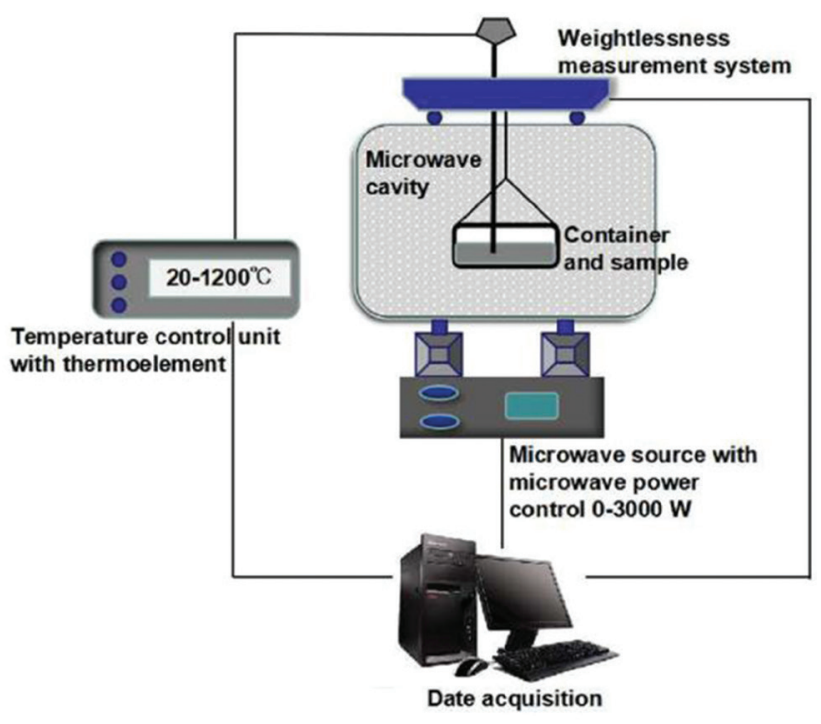

Figure 3: Schematics of microwave drying system.

container, placed inside the microwave oven, and heated at a given microwave power $(700 \mathrm{~W}, 600 \mathrm{~W}, 500 \mathrm{~W}$, or $400 \mathrm{~W})$.

\subsection{Data analysis and mathematical modeling}

The microwave drying date was calculated using the following equations:

$$
M_{t}=\frac{m_{t}-m_{g}}{m} \times 100 \%
$$

where $M_{t}$ is the moisture content at a specific time $t, \mathrm{~kg} / \mathrm{kg}$ (d.b.), $\mathrm{m}_{\mathrm{t}}$ is the mass at a specific time $\mathrm{t}$ and $\mathrm{m}_{\mathrm{g}}$ is the mass after completely drying.

$$
M_{R}=\frac{M_{t}-M_{e}}{M_{0}-M_{e}}
$$

where $M_{R}$ is the moisture ratio, $M_{0}$ is the initial moisture content, $\mathrm{kg} / \mathrm{kg}$ (d.b.) and $\mathrm{M}_{\mathrm{e}}$ is the equilibrium moisture content, $\mathrm{kg} / \mathrm{kg}$ (d.b.). The equilibrium moisture content for this material is assumed to be zero and:

$$
v_{d}=\frac{M_{t+d t}-M_{t}}{d t}
$$

where $v_{d}$ is the drying rate, $M_{t}$ and $M_{t+d t}$ are the moisture contents at $\mathrm{t}$ and $\mathrm{t}+\mathrm{dt}$ time, respectively, $\mathrm{kg} / \mathrm{kg}$ d.b.

The loss tangent $(\tan \delta)$ describes how well the material dissipates stored energy into heat at a given
Table 2: Mathematical thin-layer drying models used for the approximation.

\begin{tabular}{ll}
\hline Models & Equations \\
\hline Newton & $M_{R}=\exp (-k t)$ \\
Henderson and Pabis & $M_{R}=\operatorname{aexp}(-k t)$ \\
Page & $M_{R}=\exp \left(-k t^{n}\right)$ \\
Modified Page & $M_{R}=\exp (-k t n)$ \\
Midilli-Kucuk & $M_{R}=a \exp \left(-k t^{n}\right)+b t$ \\
Logarithmic & $M_{R}=a \exp (-k t)+c$ \\
Diffusion approach & $M_{R}=a \exp (-k t)+(1-a) \exp (-k b t)$ \\
Wang and Singh & $M_{R}=1+a t+b t^{2}$ \\
\hline
\end{tabular}

frequency and temperature. The loss tangent $(\tan \delta)$ can be expressed as:

$$
\tan \delta=\frac{\varepsilon^{\prime \prime}}{\varepsilon^{\prime}}
$$

where $\varepsilon^{\prime}$ is the dielectric constant, which reflects the ability of the material to store electromagnetic energy within its structure, $\varepsilon^{\prime \prime}$ is the dielectric loss factor that characterizes the ability of the material to convert the stored electromagnetic energy into thermal energy.

The penetration depth $\left(D_{p}\right)$ is defined as the depth at which the power of an applied microwave field is reduced to $1 / \mathrm{e}$ of its surface value and is expressed with the following equation:

$$
D_{p}=\frac{\lambda_{0}}{2 \sqrt{2} \pi \sqrt{\varepsilon^{\prime}\left[\sqrt{1+\left(\frac{\varepsilon^{\prime \prime}}{\varepsilon^{\prime}}\right)^{2}-1}\right]}}
$$

where $\lambda_{0}$ is the wavelength $\left(\lambda_{0}=12.24 \mathrm{~cm}\right.$ at $\left.2.45 \mathrm{GHz}\right)$ and $\pi$ is a constant.

The material drying is a complex heat and mass transfer process. The choice of drying model is an important part of the research work to predict the process parameters. The basic equations commonly used to describe a thin layer drying process are shown in Table 2 [28-30].

\section{Results and discussion}

\subsection{Dielectric properties of the NCR}

The dielectric constant $\left(\varepsilon^{\prime}\right)$ and loss factor $\left(\varepsilon^{\prime \prime}\right)$ of NCR were measured at various of temperature $\left(20-180^{\circ} \mathrm{C}\right)$ for different of moisture contents and the results are shown in Figure 4a. The dielectric loss angle tangent $(\tan \delta)$ 
was calculated according to: $\tan \delta=\varepsilon " / \varepsilon$ ' and is shown in Figure $4 \mathrm{~b}$. From Figures $4 \mathrm{a}$ and $4 \mathrm{~b}$, both $\varepsilon^{\prime}$ and $\varepsilon$ '” increased remarkably from 2.7541 to 14.5374 and 0.0374 to 2.991, respectively, when the moisture content increased to $14 \%$. In the meantime, $\tan \delta$ gradually increased from 0.0141 to 0.2057 . The increase of $\varepsilon$ ' and $\varepsilon$ " with the moisture content also occurs in certain waste residues. For example, the moisture content of $\mathrm{CuCl}$ residue is $10-15 \%$ and its dielectric constant at room temperature is higher than 14 [24]. In general, with the increase of moisture content the absorbency of materials has been significantly improved, which means that the microwave drying efficiency will be higher.

As shown in Figures $4 \mathrm{c}$ and $4 \mathrm{~d}$, the $\varepsilon$ ' and $\varepsilon$ " of the dried sample do not change much with the increasing temperature in the $20-180^{\circ} \mathrm{C}$ range. This phenomenon also occurs in certain metallurgical residues, such as spent adsorbent with zinc sulfate [25] and molybdenite concentrate [26]. By comparison with the dielectric constant of water at room temperature of 78 and a loss factor of 16.2, Figures $4 \mathrm{a}, 4 \mathrm{c}$ and $4 \mathrm{~d}$ show that the dielectric properties of the material is strongly associated with the moisture content. Therefore, the microwave energy is mainly absorbed by the water molecules that evaporate during the drying process and the material consumes less energy. Therefore, the efficiency of the microwave heating for water evaporation is higher.

The values of penetration depth $\left(D_{p}\right)$ for different moisture content and temperature were calculated using Eq. 5 and shown in Figures 4e and 4f. The moisture content has obvious effect on the $\mathrm{D}_{\mathrm{p}}$, within the measurement range, the $\mathrm{D}_{\mathrm{p}}$ decreases rapidly from $82.6 \mathrm{~cm}$ to $2.4 \mathrm{~cm}$ with the increase of moisture content, while temperature has little effect on the $D_{p}$, and the values are above $84 \mathrm{~cm}$. In this drying experiment the sample was shaped into a $10 \mathrm{~mm}$ thin layer, the penetration depth of microwave has little influence on the drying process, but in the follow-up industrialization experiment must pay attention to the sample thickness.

\subsection{Energy balance analysis in a micro-section of the NCR}

The heat balance of the drying process mainly considers energy introduction and dissipation. The thermal and mass equilibrium between the water, the gas, and the matrix were proposed by Suwannapum [31] and Prat [32]. In consideration of their study, we performed an energy balance analysis on the microsection of porous NCR, as shown in Figure 5. The thermal equilibrium analysis was performed with the thin-layer micro-section of $\partial x \partial z$.

The heat input of the system consists of two parts. The first one is the heat transfer in other micro-sections of the system. The second one is the conversion of the microwave energy into internal energy during the heating process. They can be expressed by the following formula:

$$
\begin{aligned}
& Q=2 \pi f E_{y}^{2} \varepsilon_{0} \varepsilon^{\prime \prime} \\
& q=\frac{\partial}{\partial x}\left[\lambda_{\text {eff }} \frac{\partial T}{\partial x}\right]+\frac{\partial}{\partial z}\left[\lambda_{\text {eff }} \frac{\partial T}{\partial z}\right]
\end{aligned}
$$

where $Q$ is the heat generated by the absorption of the microwaves, $\mathrm{f}$ is the frequency of the microwave $(\mathrm{Hz}), \mathrm{E}_{\mathrm{y}}$ is the electric field intensity in the y direction $(\mathrm{V} / \mathrm{m}), \varepsilon_{0}$ is permittivity of free space: $8.854(\mathrm{pF} / \mathrm{m}), \mathrm{q}$ is the heat transfer in the other micro-sections, $\lambda_{\text {eff }}$ is the effective thermal conductivity $(\mathrm{W} / \mathrm{m} \cdot \mathrm{K})$, and $\mathrm{T}$ is the temperature (K).

The heat loss includes the following three parts:

1. Heating of the material mixture

$$
q_{1}=\frac{\partial}{\partial t}\left[\left(\rho C_{p}\right)_{T} T\right]
$$

where $\left(\rho C_{p}\right) T$ is the effective heat capacitance of the watergas matrix mixture:

$$
\left(\rho C_{\mathrm{p}}\right)_{T}=\rho_{l} C_{\mathrm{pl}} \varphi s+\rho_{\mathrm{g}} C_{\mathrm{pg}} \varphi(1-s)+\rho_{p} C_{\mathrm{pp}}(1-\varphi)
$$

where $t$ is the time (s), $\rho$ is density and $C_{p}$ is specific heat capacity. $\rho_{\mathrm{l}}, \rho_{\mathrm{a}}, \rho_{\mathrm{p}}$ are the density of liquid water, air and residue particle, respectively $\left(\mathrm{kg} / \mathrm{m}^{3}\right) . \mathrm{C}_{\mathrm{pl}}, \mathrm{C}_{\mathrm{pa}}, \mathrm{C}_{\mathrm{pp}}$ are the specific heat capacity of liquid water, air and residue particle, respectively $(\mathrm{J} / \mathrm{kg} \cdot \mathrm{K}) . \varphi$ is the porosity and $\mathrm{s}$ is the water saturation.

2. Heat loss caused by air, water, and vapor escape

$$
\begin{aligned}
q_{2}= & \frac{\partial}{\partial x}\left\{\left[\rho_{l} C_{p l} u_{l}+\left(\rho_{a} C_{p a}+\rho_{v} C_{p v}\right) u_{g}\right] T\right\}+ \\
& \frac{\partial}{\partial \mathrm{z}}\left\{\left[\rho_{l} C_{p l} w_{l}+\left(\rho_{a} C_{p a}+\rho_{v} C_{p v}\right) w_{g}\right] T\right\}
\end{aligned}
$$

where $\rho_{v}$ is the density of water vapor $\left(\mathrm{kg} / \mathrm{m}^{3}\right), \mathrm{C}_{\mathrm{pv}}$ is the specific heat capacity of water vapor $(\mathrm{J} / \mathrm{kg} \cdot \mathrm{K}) . \mathrm{u}_{1}$ and $\mathrm{u}_{\mathrm{g}}$ are the velocity of liquid water and the gas phase in the $\mathrm{x}$ direction $(\mathrm{m} / \mathrm{s})$, respectively. $\mathrm{w}_{\mathrm{l}}$ and $\mathrm{w}_{\mathrm{g}}$ are the velocity of liquid water and the gas phase in the $\mathrm{z}$ direction $(\mathrm{m} / \mathrm{s})$, respectively. 


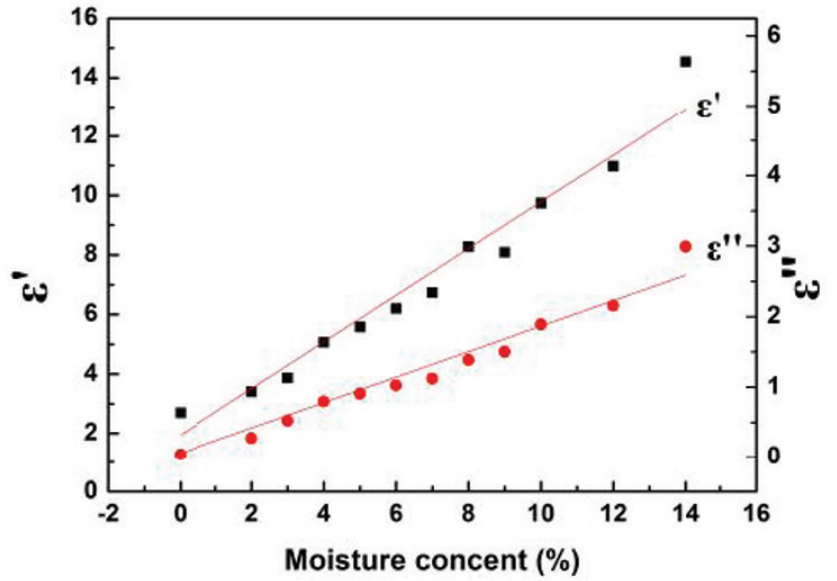

(a)

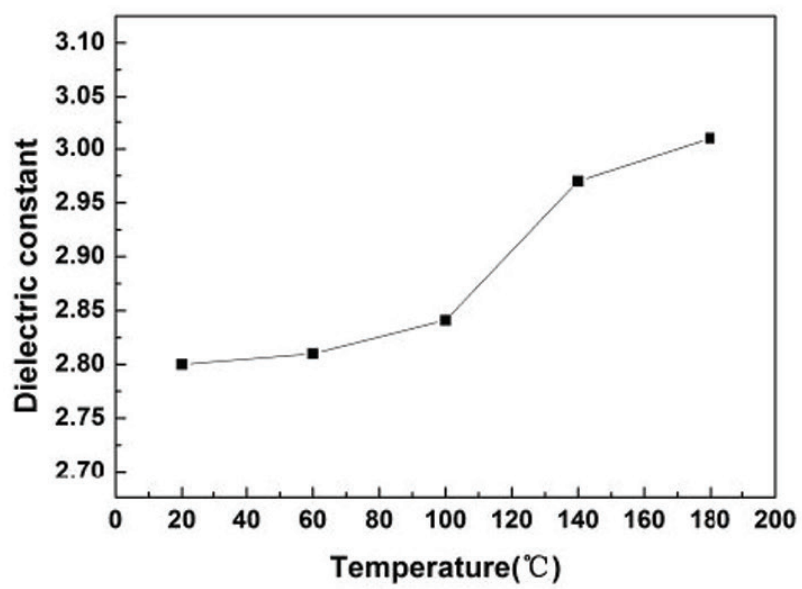

(c)

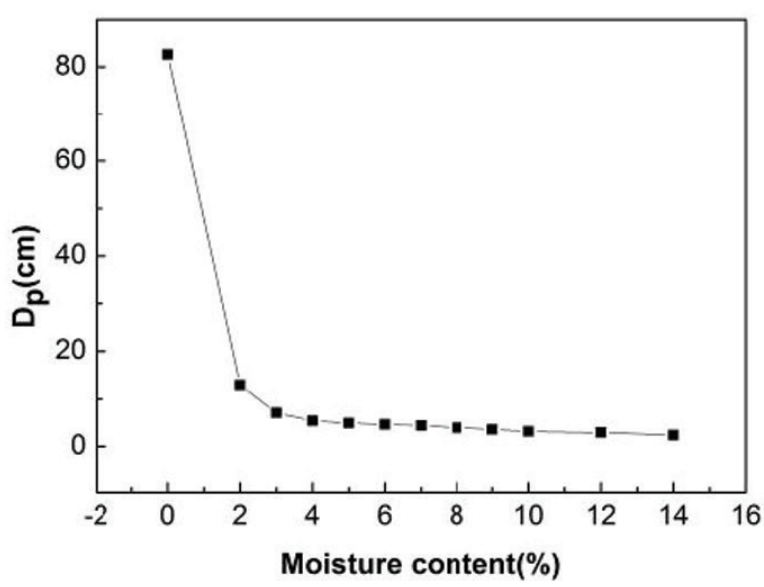

(e)

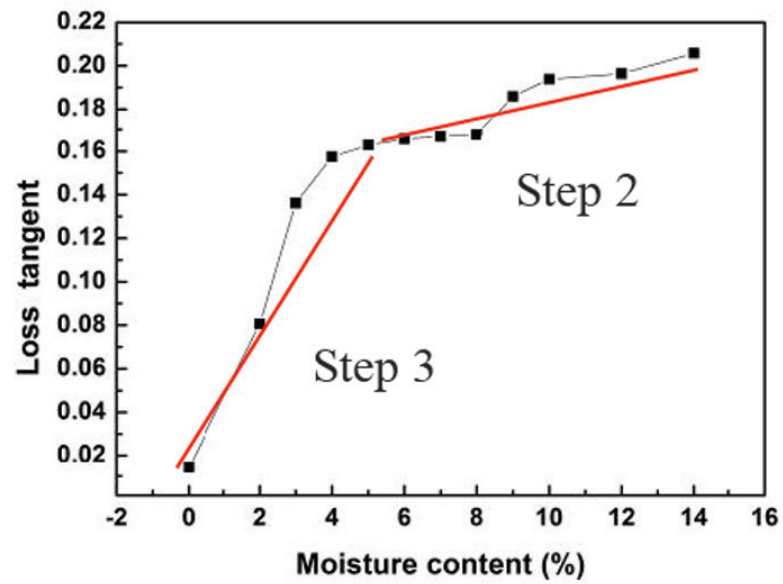

(b)

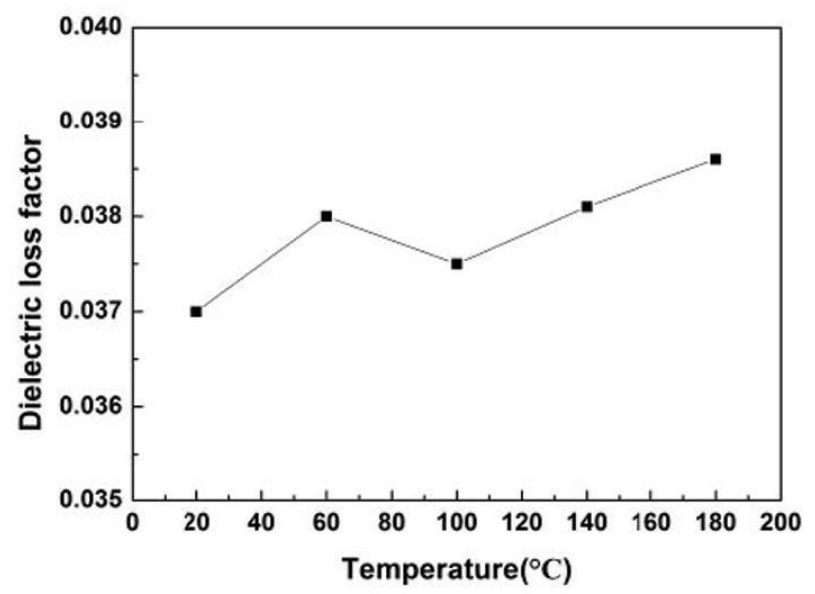

(d)

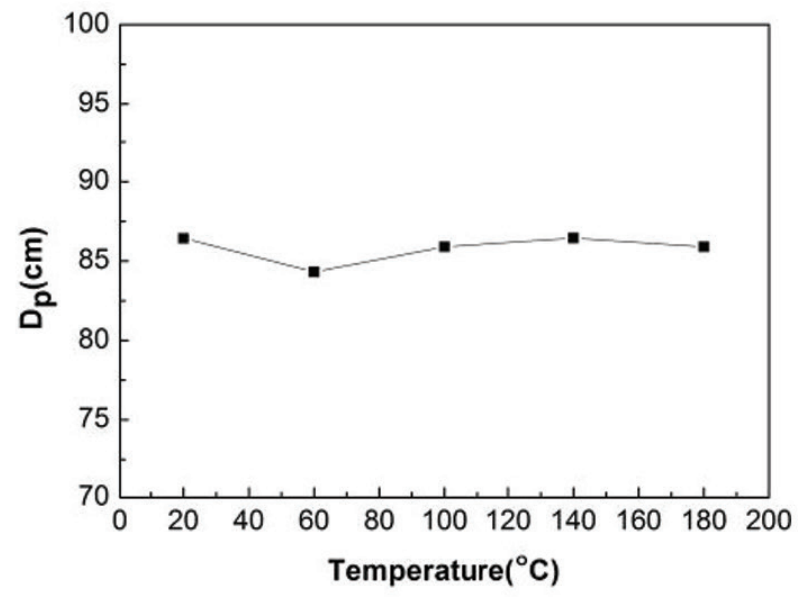

(f)

Figure 4: Dielectric properties of the NCR for different moisture content and temperature. (a) Dielectric constant ( $\left.\varepsilon^{\prime}\right)$ and loss factor $(\varepsilon ")$ for different moisture content. (b) Dielectric loss angle tangent (tan $\delta)$ for different moisture content. (c,d) Dielectric constant $\left(\varepsilon\right.$ ') and loss factor $\left(\varepsilon\right.$ ") for the dried sample at different temperature. (e,f) Penetration depth $\left(D_{p}\right)$ for different moisture content and temperature. 
3. Latent heat of vaporization

$$
q_{3}=H_{v} \cdot \dot{m}
$$

where $H_{v}$ is the latent heat of evaporation $(\mathrm{J} / \mathrm{kg})$ and $\dot{m}$ is the phase change term $\left(\mathrm{kg} / \mathrm{m}^{3} \cdot \mathrm{s}\right)$ expressed as [24]:

$$
\begin{aligned}
& \dot{m}=\frac{\partial}{\partial t}\left[\rho_{v} \varphi(1-s)\right]+\frac{\partial}{\partial x}\left[-D_{m} \frac{\partial \rho_{v}}{\partial x}\right]+ \\
& \frac{\partial}{\partial z}\left[\rho_{v} \frac{K K_{r g}}{\mu_{g}} \rho_{g} g_{z}-D_{m} \frac{\partial \rho_{v}}{\partial x}\right]
\end{aligned}
$$

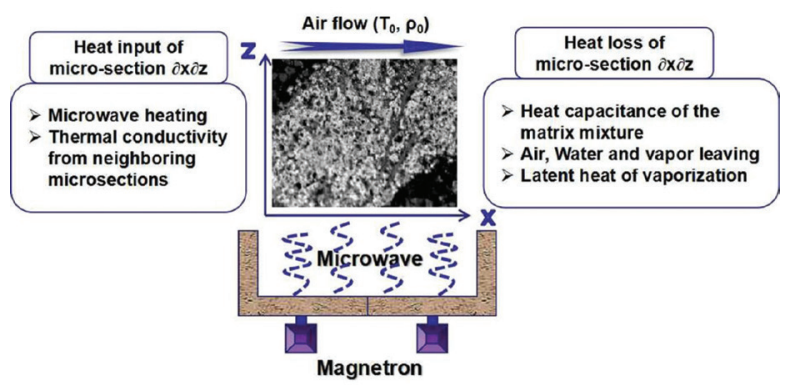

Figure 5: Energy balance analysis in a micro-section of NCR. where, $D_{m}$ is the effective molecular mass diffusion $\left(\mathrm{m}^{2} / \mathrm{s}\right), \mathrm{K}$ is the permeability $\left(\mathrm{m}^{2}\right), \mathrm{K}_{\mathrm{rg}}$ is the relative gas permeability $\left(\mathrm{m}^{2}\right), \mu_{\mathrm{g}}$ is the gas dynamic viscosity $(\mathrm{Pa} \cdot \mathrm{s})$, and $g_{z}$ is the gas of direction $z$.

Therefore, the total heat balance of the micro-section can be described as:

$$
\begin{aligned}
& \frac{\partial}{\partial \mathrm{t}}\left[\left(\rho C_{p}\right)_{T} T\right]+H_{v} \cdot \dot{m}+ \\
& \frac{\partial}{\partial x}\left\{\left[\rho_{l} C_{p l} u_{l}+\left(\rho_{a} C_{p a}+\rho_{v} C_{p v}\right) u u_{g}\right] T\right\}+ \\
& \frac{\partial}{\partial z}\left\{\left[\rho_{l} C_{p l} w_{l}+\left(\rho_{a} C_{p a}+\rho_{v} C_{p p}\right) w_{g}\right] T\right\} \\
& =2 \pi f E_{y}^{2} \varepsilon_{0} \varepsilon+\frac{\partial}{\partial x}\left[\lambda_{\text {eff }} \frac{\partial T}{\partial x}\right]+\frac{\partial}{\partial z}\left[\lambda_{\text {eff }} \frac{\partial T}{\partial z}\right]
\end{aligned}
$$

\subsection{Microwave drying kinetics of the NCR}

Figures $6 \mathrm{a}$ and $6 \mathrm{c}$ show that the moisture content of NCR significantly decreases with the decrease of sample mass and the increase of microwave power. A similar rule was mentioned by several researchers for different materials

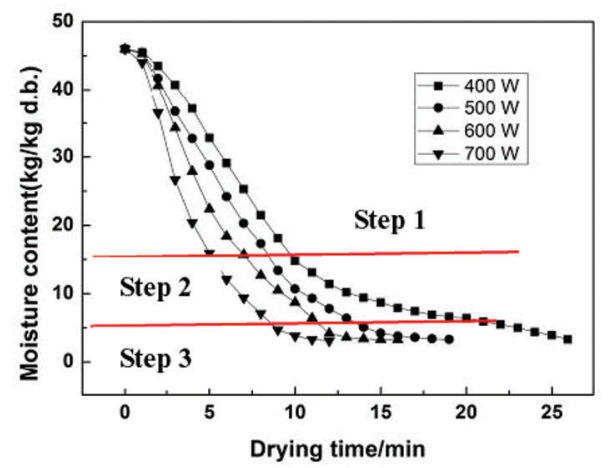

(a)

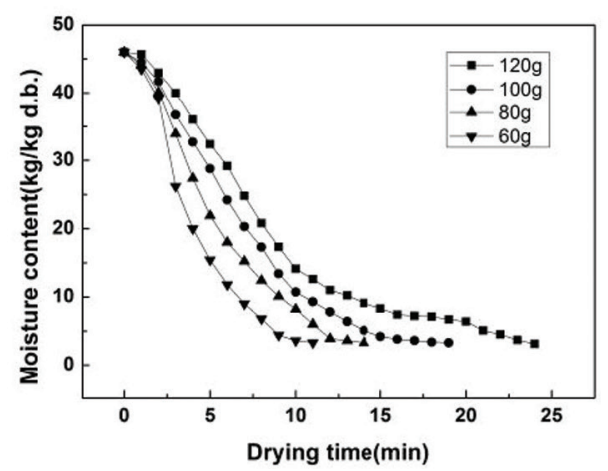

(c)

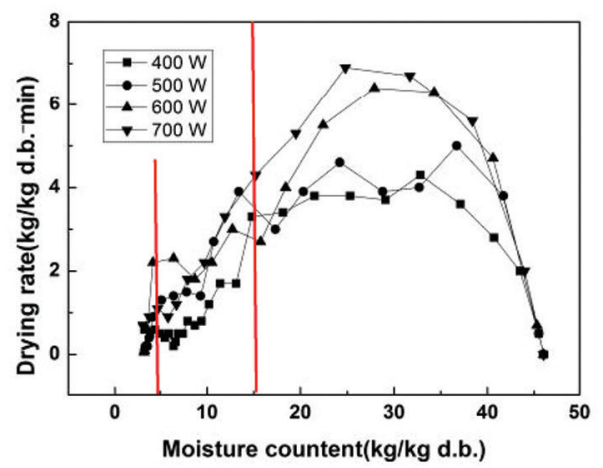

(b)

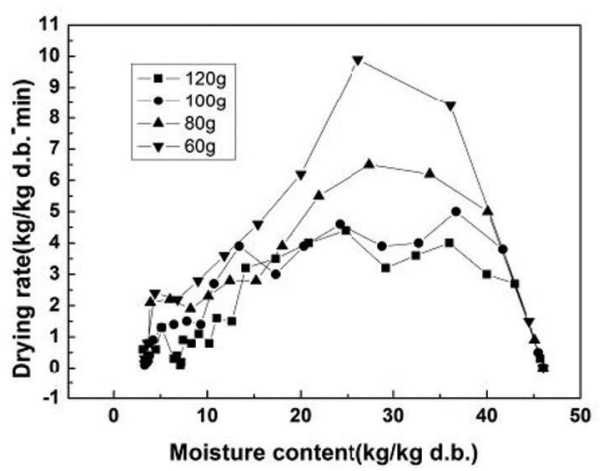

(d)

Figure 6: Microwave drying curves of NCR. (a) Drying curves of $100 \mathrm{~g}$ sample at different microwave powers, (b) drying rate curves of $100 \mathrm{~g}$ sample at different microwave powers, (c) drying curves with a different sample mass at $500 \mathrm{~W}$ and (d) drying rate curves with a different sample mass at $500 \mathrm{~W}$. 
dried using microwave energy [33,34]. According to various microwave power and material mass, it will take 14 to $28 \mathrm{~min}$ to remove the water of the NCR from $45.8 \%$ to $0.3 \% \mathrm{~kg} / \mathrm{kg}$ (d.b.). Figures $6 \mathrm{~b}$ and $6 \mathrm{~d}$ illustrate the significant impact of the microwave power and material mass on the drying rate. At a power of $400 \mathrm{~W}$ and $500 \mathrm{~W}$ or a mass of $100 \mathrm{~g}$ and $120 \mathrm{~g}$, the drying rate is close unlike at other conditions. After a short period of heating, the values of drying rate of the process changed from rapid increase to a constant. The constant rate stage occurred form nearly $3.8 \%$ to about $4.3 \% \mathrm{~kg} / \mathrm{kg}$ (d.b.) per min and was followed by a stage of decreasing drying rate period where the internal diffusion of water molecules becomes the limiting link in drying [35].

Table 3: Statistical analysis of each model at various microwave powers.

\begin{tabular}{|c|c|c|c|c|c|c|}
\hline Model & Power (W) & $\mathbf{R}^{2}$ & SSR & Mass (g) & $\mathbf{R}^{2}$ & SSR \\
\hline \multirow[t]{4}{*}{ Newton } & 400 & 0.9618 & 0.0918 & 120 & 0.9622 & 0.0972 \\
\hline & 500 & 0.9573 & 0.0891 & 100 & 0.9573 & 0.0891 \\
\hline & 600 & 0.9609 & 0.0697 & 80 & 0.9583 & 0.0647 \\
\hline & 700 & 0.9683 & 0.0480 & 60 & 0.9600 & 0.0517 \\
\hline \multirow[t]{4}{*}{ Henderson and Pabis } & 400 & 0.9786 & 0.0493 & 120 & 0.9785 & 0.0533 \\
\hline & 500 & 0.9756 & 0.0481 & 100 & 0.9756 & 0.0481 \\
\hline & 600 & 0.9773 & 0.0379 & 80 & 0.9750 & 0.0360 \\
\hline & 700 & 0.9801 & 0.0279 & 60 & 0.9726 & 0.0322 \\
\hline \multirow[t]{4}{*}{ Page } & 400 & 0.9851 & 0.0338 & 120 & 0.9825 & 0.0433 \\
\hline & 500 & 0.9964 & 0.0071 & 100 & 0.9964 & 0.0071 \\
\hline & 600 & 0.9941 & 0.0098 & 80 & 0.9954 & 0.0068 \\
\hline & 700 & 0.9926 & 0.0093 & 60 & 0.9916 & 0.0099 \\
\hline \multirow[t]{4}{*}{ Modified Page } & 400 & 0.9601 & 0.0918 & 120 & 0.9607 & 0.0972 \\
\hline & 500 & 0.9549 & 0.0891 & 100 & 0.9549 & 0.0891 \\
\hline & 600 & 0.9584 & 0.0697 & 80 & 0.9551 & 0.0647 \\
\hline & 700 & 0.9658 & 0.0480 & 60 & 0.9560 & 0.0517 \\
\hline \multirow[t]{4}{*}{ Logarithmic } & 400 & 0.9788 & 0.0468 & 120 & 0.9778 & 0.0528 \\
\hline & 500 & 0.9838 & 0.0303 & 100 & 0.9838 & 0.0303 \\
\hline & 600 & 0.9835 & 0.0257 & 80 & 0.9857 & 0.0190 \\
\hline & 700 & 0.9828 & 0.0223 & 60 & 0.9786 & 0.0226 \\
\hline \multirow[t]{4}{*}{ Diffusion approach } & 400 & 0.9671 & 0.0725 & 120 & 0.9649 & 0.0834 \\
\hline & 500 & 0.9747 & 0.0471 & 100 & 0.9747 & 0.0471 \\
\hline & 600 & 0.9747 & 0.0396 & 80 & 0.9778 & 0.0296 \\
\hline & 700 & 0.9756 & 0.0317 & 60 & 0.9706 & 0.0310 \\
\hline \multirow[t]{4}{*}{ Wang and Singh } & 400 & 0.9768 & 0.0535 & 120 & 0.9762 & 0.0589 \\
\hline & 500 & 0.9836 & 0.0323 & 100 & 0.9836 & 0.0323 \\
\hline & 600 & 0.9834 & 0.0278 & 80 & 0.9833 & 0.0241 \\
\hline & 700 & 0.9845 & 0.0218 & 60 & 0.9795 & 0.0241 \\
\hline \multirow[t]{8}{*}{ Midilli-Kucuk } & $400 W$ & \multicolumn{3}{|c|}{$a=1.0213 ; k=0.0318 ; n=1.5706 ; b=0.0042$} & 0.9958 & 0.0095 \\
\hline & $500 \mathrm{~W}$ & \multicolumn{3}{|c|}{$a=1.0097 ; k=0.0411 ; n=1.5915 ; b=0.0029$} & 0.9993 & 0.0011 \\
\hline & $600 W$ & \multicolumn{3}{|c|}{$a=1.0252 ; k=0.0660 ; n=1.4864 ; b=0.0031$} & 0.9968 & 0.0046 \\
\hline & $700 \mathrm{~W}$ & \multicolumn{3}{|c|}{$a=1.0162 ; k=0.0803 ; n=1.5057 ; b=0.0053$} & 0.9959 & 0.0023 \\
\hline & $120 \mathrm{~g}$ & \multicolumn{3}{|c|}{$a=1.0185 ; k=0.0332 ; n=1.5679 ; b=0.0043$} & 0.9953 & 0.0098 \\
\hline & $100 \mathrm{~g}$ & \multicolumn{3}{|c|}{$a=1.0097 ; k=0.0411 ; n=1.5915 ; b=0.0029$} & 0.9993 & 0.0011 \\
\hline & $80 \mathrm{~g}$ & \multicolumn{3}{|c|}{$a=1.0241 ; k=0.0693 ; n=1.4706 ; b=0.0027$} & 0.9967 & 0.0040 \\
\hline & $60 \mathrm{~g}$ & \multicolumn{3}{|c|}{$a=1.0261 ; k=0.1067 ; n=1.5070 ; b=0.0054$} & 0.9961 & 0.0051 \\
\hline
\end{tabular}


The moisture content of NCR reduced from $15 \%$ to $0.3 \% \mathrm{~kg} / \mathrm{kg}$ (d.b.) at power of $600 \mathrm{~W}$ and $700 \mathrm{~W}$ or mass of $60 \mathrm{~g}$ and $80 \mathrm{~g}$ in the decreasing stage. The reason is that a higher temperature of the NCR will be received at higher power densities, leading to quick drying. These results were in agreement with the study on parsley leaf drying by Soysal et al. [36].

As shown in Table 3 and Figure 7, eight thinlayer drying models as mentioned above were used to analyze the drying kinetics. After date fitting, it is found that Midilli-Kucuk model is the most suitable for experimental data with a determination coefficient $\left(\mathrm{R}^{2}\right)$ of over 0.9958 and a sum of squared residuals (SSR) lower than 0.0095 . The value of the drying constant $k$ increases with the increase of power density (microwave power/material mass). This implies that the drying curve becomes steeper with increasing microwave power. The $\mathrm{a}, \mathrm{n}$, and $\mathrm{b}$ parameters of the Midilli-Kucuk model were almost the same for all drying conditions. This means that the parameters $\mathrm{a}, \mathrm{n}$ and $\mathrm{b}$ can be assumed constant and equal to 1.0188, 1.5363, and 0.0038 , respectively.

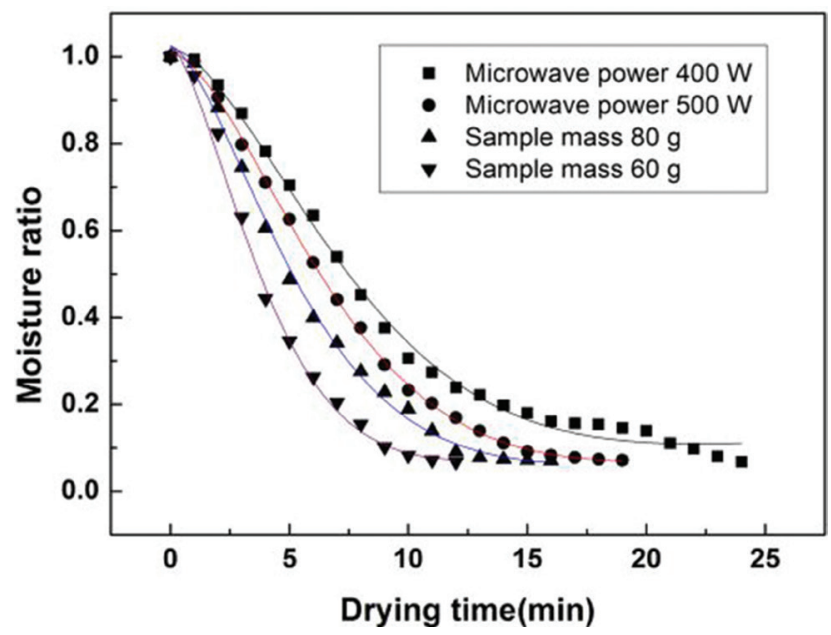

Figure 7: Comparison of the experimental date with the predicted Midilli-Kucuk equation.

\subsection{Estimation of the activation energy}

An exponential expression based on the Arrhenius equation was used to calculate the activation energy for the drying process

$$
\mathrm{k}=\mathrm{k}_{0} \exp \left(\frac{-E_{\mathrm{a}} \cdot \mathrm{m}}{P}\right)
$$

where $\mathrm{k}$ and $\mathrm{k}_{0}$ is corresponding to the drying rate constant and pre-exponential factor $\left(\mathrm{min}^{-1}\right)$. Ea is the activation energy $\left(\mathrm{W} \cdot \mathrm{g}^{-1}\right)$. $\mathrm{m}$ and $\mathrm{P}$ are corresponding to microwave power (W) and sample mass (g), respectively. The linear fitting according to Eq. 12 between $\ln (\mathrm{k})$ and $\mathrm{m} / \mathrm{P}$ is shown in Figure 8 with SSR and $\mathrm{R}^{2}$ values of 0.0239 and 0.9794, respectively. Afterwards, $\mathrm{k}_{0}$ and $\mathrm{E}_{\mathrm{a}}$ were determined at $0.3321 \mathrm{~min}^{-1}$ and $9.7604 \mathrm{~W} \cdot \mathrm{g}^{-1}$, respectively. $\mathrm{k}$ can be calculated using these estimated values for the desired power and mass. By this, the moisture ratio of NCR can be estimated at any given time during microwave drying or vice and versa using the values of $\mathrm{k}$ calculated with the Midilli-Kucuk model and the constant values of the $\mathrm{a}, \mathrm{n}$, and $\mathrm{b}$ discussed earlier.

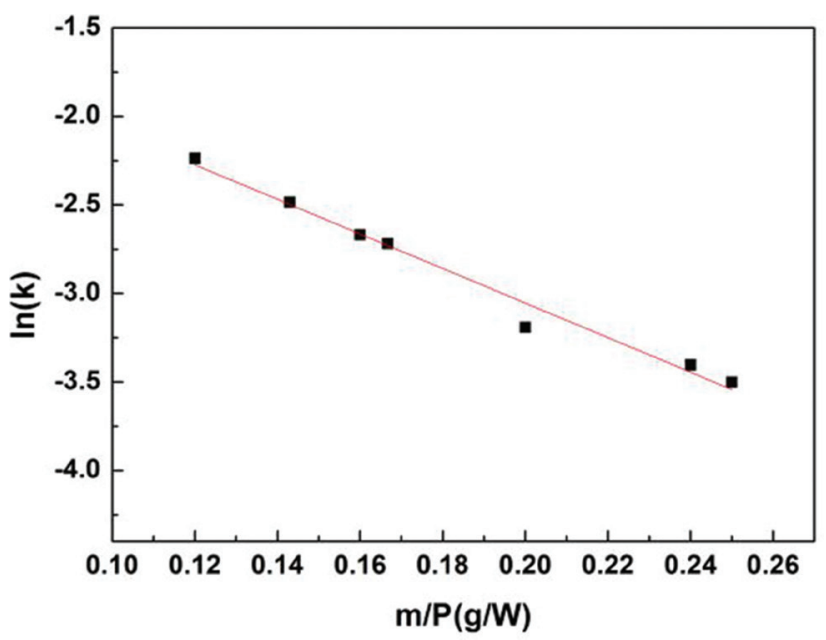

Figure 8: Evolution of the $\ln (\mathrm{k})$ with the mass/power ratio $(\mathrm{m} / \mathrm{P})$.

Table 4: Microwave drying stage division.

\begin{tabular}{lll}
\hline Step (moisture content) & Dielectric properties as Figure 4 & Drying stage as Figure 6 \\
\hline 1. Above 15\% & Strongly associated with the moisture content & Accelerating drying stage + Constant drying stage \\
2. 6-15\% & Strongly associated with the moisture content & Decelerating drying stage \\
3. Below 6\% & Relatively weak absorption capacity & Difficult drying stage \\
\hline
\end{tabular}




\subsection{Energy consumption statistics and optimization}

According to the dielectric properties of NCR and dynamic simulation, the microwave drying processes of NCR can be divided into three stages, which is shown in Table 4.

During the optimization experiment, $100 \mathrm{~g}$ material is dried in $10 \mathrm{~mm}$ thin layer, and finally dried to $3.3 \%$. The response surface methodology (RSM) is used to optimize the microwave power input in three stages for the drying processing of NCR with low energy consumption. The energy consumption $(y)$ is chosen as the dependent

Table 5: Experimental design matrix and result.

\begin{tabular}{lcccc}
\hline Run & Step1 (W) & Step1 $(\mathbf{W})$ & Step1 (W) & Step1 $(\mathbf{W} \cdot \mathbf{h})$ \\
\hline 1 & 400 & 700 & 550 & 181.6 \\
2 & 700 & 400 & 550 & 193.3 \\
3 & 550 & 550 & 550 & 176.3 \\
4 & 550 & 700 & 400 & 172.2 \\
5 & 550 & 400 & 400 & 187.5 \\
6 & 400 & 550 & 400 & 151.6 \\
7 & 400 & 550 & 700 & 153.3 \\
8 & 700 & 550 & 700 & 150.2 \\
9 & 400 & 400 & 550 & 196.6 \\
10 & 550 & 550 & 550 & 176.7 \\
11 & 550 & 550 & 550 & 177.1 \\
12 & 550 & 550 & 550 & 175.8 \\
13 & 550 & 400 & 700 & 189.6 \\
14 & 550 & 550 & 550 & 174.1 \\
15 & 700 & 550 & 400 & 157.9 \\
16 & 700 & 700 & 550 & 178.6 \\
17 & 550 & 700 & 700 & 175.6 \\
\hline
\end{tabular}

variable, while microwave input power at each stage ( $\chi_{1}$, $X_{2}, X_{3}$ ) is chosen as three independent variables and the exact experimental conditions are shown in Table 5.

Table 6 shows the analysis of statistical data of the significant quadratic predictive model. The $\mathrm{R}^{2}$ is 0.9895 , indicating that only $2.05 \%$ of the variations is outside the model. And a high value of adjusted determination coefficient (adjusted $\mathrm{R}^{2}=0.9760$ ) also indicating the model is significant. In addition, the model F-value of 73.3 and P-value less than 0.0001 show that model is significant. The coefficient of variation is low ( $\mathrm{CV}=1.25 \%)$, indicating that the experimental value has a high accuracy.

As Table 7 and Figure 9 show, the optimum microwave power in each stage is identified to be $700 \mathrm{~W}, 550 \mathrm{~W}$ and $400 \mathrm{~W}$. We repeated the experiment at the optimized conditions obtained an average energy consumption of $158.3 \mathrm{~W} \cdot \mathrm{h}$ and found that the deviations between the experimental value and the predicted value is small.

Stage 1, preheating and steaming stage: Large amounts of water in the sample need more microwave energy to evaporate.

Stage 2, decelerating drying stage: Water content decreased, but the diffusion process is smooth. In this stage, only the latent heat of vaporization which is supplied by microwave power is needed.

Stage 3, internal diffusion stage: With the decrease of free water, only capillary water is left in the material and

Table 7: Energy consumption statistics under the optimized conditions.

\begin{tabular}{lcccc}
\hline Step 1 (W) & Step 2 (W) & Step 3 (W) & \multicolumn{2}{c}{ Energy consumption $(W \cdot h)$} \\
\cline { 3 - 5 } & & & Predicted & Experimental \\
\hline 700.000 & 550.000 & 400.000 & 155.2 & 158.3 \\
\hline
\end{tabular}

Table 6: Variance (ANOVA) analysis for quadratic model.

\begin{tabular}{lccccccc}
\hline Source & Coefficient & Standard error & Sum of squares & df & Mean square & F-value & p-value Prob $>$ F \\
\hline Model & 176.00 & 0.98 & 3135.77 & 9 & 348.42 & 73.30 & $<0.0001$ \\
$\chi_{1}$ & -0.39 & 0.77 & 1.20 & 1 & 1.20 & 0.25 & 0.6306 \\
$\chi_{2}$ & -7.38 & 0.77 & 435.13 & 1 & 435.13 & 91.54 & $<0.0001$ \\
$\chi_{3}$ & -0.063 & 0.77 & 0.031 & 1 & 0.031 & 0.00657 & 0.9376 \\
$\chi_{1} \chi_{2}$ & 0.075 & 1.09 & 0.023 & 1 & 0.023 & 0.00473 & 0.9471 \\
$\chi_{1} \chi_{3}$ & -2.35 & 1.09 & 22.09 & 1 & 22.09 & 4.65 & 0.0680 \\
$\chi_{2} \chi_{3}$ & 0.33 & 1.09 & 0.42 & 1 & 0.42 & 0.089 & 0.7743 \\
$\chi_{1}^{2}$ & -8.22 & 1.06 & 284.84 & 1 & 284.84 & 59.93 & 0.0001 \\
$\chi_{2}{ }^{2}$ & 19.75 & 1.06 & 1642.37 & 1 & 1642.37 & 345.53 & $<0.0001$ \\
$\chi_{3}{ }^{2}$ & -14.53 & 1.06 & 888.32 & 1 & 888.32 & 186.89 & $<0.0001$ \\
\hline
\end{tabular}

$R^{2}=0.9895 ; \operatorname{adj} . R^{2}=0.9760 ; C V=1.25 \%$. 


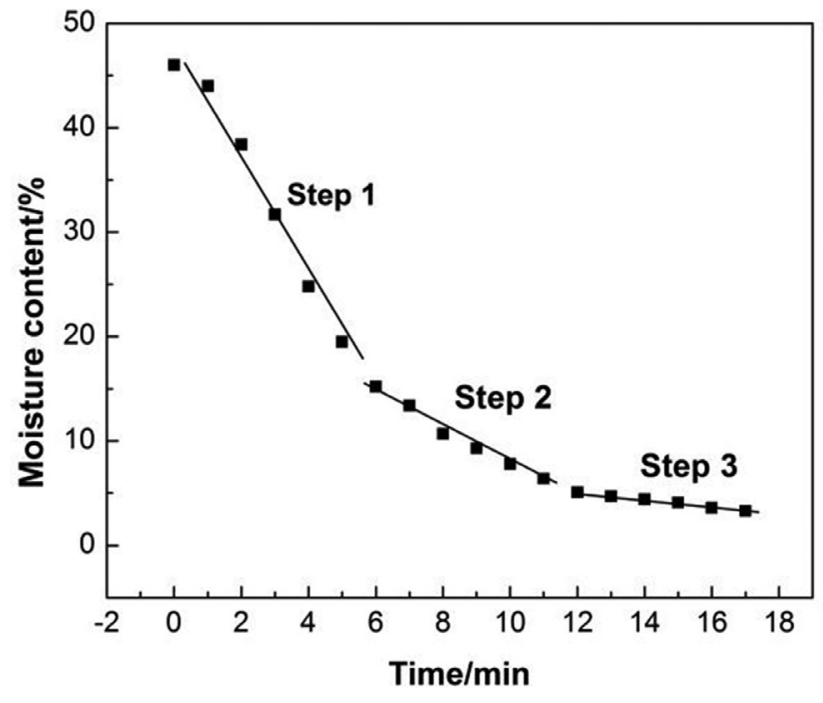

Figure 9: Optimized microwave drying process.

a dense crust will form on the surface of the material in the last stage stage. While the water content of the NCR is not sufficient to absorb the microwave energy, therefore a burning period is possible to appear with the microwave distribution inside the material becomes more and more uneven. So a lower microwave power and longer drying time is needed.

Changing the microwave power in the drying process can effectively reduce energy consumption. According to the optimized process, the energy consumption above of $110 \mathrm{~W} \cdot \mathrm{h} / \mathrm{kg}$ can be reduced than that of drying with a single microwave power. It can provide effective basic data for industrialization experiment.

\section{Conclusion}

1. The dielectric properties of a NCR with various moisture contents were measured at low temperatures. And found that the dielectric properties of the material are strongly related to the moisture content. During the drying process, the microwave energy is mainly absorbed by the water molecules.

2. The drying characteristics of the NCR were studied at different microwave powers and various sample masses. The variations in moisture content, drying rate, and moisture ratio were significantly affected by the power density.

3. The Midilli-Kucuk model was used to describe the drying characteristics of the NCR with a high value of $R^{2}$ and low value of SSR. The values of $k_{0}$ and $E_{a}$ were received as $0.3321 \mathrm{~min}^{-1}$ and $9.7604 \mathrm{~W} \cdot \mathrm{g}^{-1}$ using the Arrhenius equation. They correctly described the dependence of the drying rate constant on the powers/ mas ration $\mathrm{P} / \mathrm{m}$. In actual production, it can be used to predict and control the drying rate and moisture content at any time for a given power and sample mass.

4. By adjusting the microwave power in the drying process, the energy consumption above of $110 \mathrm{~W} \cdot \mathrm{h} / \mathrm{kg}$ can be reduced.

Acknowledgments: This work was funded by Foundation of Henan Educational Committee (Grant No. 18A530002) and Key Scientific and Technological Project of Henan Province (Grant No. 182102310896).

\section{References}

[1] Shinyama K., Magari Y., Tanaka T., Nakamura H., Nohma T., Yonezu I., Influence of electroless nickel plating of hydrogenabsorbing alloys on cycle characteristics of nickel-metal hydride batteries. Res. Chem. Intermediat., 2006, 32, 419-429.

[2] Basch A., Albering J.H., Preparation and characterization of core-shell battery materials for Li-ion batteries manufactured by substrate induced coagulation. J. Power Sources, 2011, 196, 3290-3295.

[3] Adhoum N., Monser L., Bellakhal N., Belgaied J., Treatment of electroplating wastewater containing $\mathrm{Cu}^{2+}, \mathrm{Zn}^{2+}$, and $\mathrm{Cr}(\mathrm{VI})$ by electrocoagulation. J. Hazard. Mater., 2004, 112, 207-213.

[4] Yan X., Li Q., Chai L., Wang Q., Formation of abiological granular sludge - a facile and bioinspired proposal for improving sludge settling performance during heavy metal wastewater treatment. Chemosphere, 2014, 113, 36-41.

[5] Akbal F., Camcl S., Copper, chromium and nickel removal from metal plating wastewater by electrocoagulation. Desalination, 2011, 269, 214-222.

[6] Hsieh C.H., Shih K., Hu C.Y., Lo S.L., Li N.H., Cheng Y.T., The effects of salinity and temperature on phase transformation of copper-laden sludge. J. Hazard. Mater., 2013, 244-245, 501-506.

[7] Zhang P., Ma Y., Xie F., Impacts of ultrasound on selective leaching recovery of heavy metals from metal-containing waste sludge. J. Mater. Cycles Waste, 2013, 15, 530-538.

[8] Silva J.E., Paiva A.P., Soares D., Labrincha A., Castro F., Solvent extraction applied to the recovery of heavy metals from galvanic sludge. J. Hazard. Mater., 2005, 120, 113-118.

[9] Liang Y.J., Chai L.Y., Min X.B., Tang C.J., Zhang H.J., Ke Y., et al., Hydrothermal sulfidation and floatation treatment of heavymetal-containing sludge for recovery and stabilization. J. Hazard. Mater., 2012, 217-218, 307-314.

[10] Shih K., White T., Leckie J.O., Nickel stabilization efficiency of aluminate and ferrite spinels and their leaching behavior. Environ. Sci. Technol., 2006, 40, 5520-5526. 
[11] Luan J., Li R., Zhang Z., Li Y., Zhao L., Speciation evolutions of target metals $(\mathrm{Cd}, \mathrm{Pb})$ influenced by chlorine and sulfur during sewage sludge incineration. Front. Env. Sc. Eng., 2014, 8, 871-876.

[12] Mortier S.T.F.C., De Beer T., Gernaey K.V., Remon P.J., Vervaet C., Nopens I., Mechanistic modelling of fluidized bed drying processes of wet porous granules: a review. Eur. J. Pharm. Biopharm., 2011, 79, 205-225.

[13] Hossain M.A., Gottschalk K., Amer B.M.A., Mathematical modelling for drying of tomato in hybrid dryer. Arab. J. Sci. Eng., 2010, 35, 239.

[14] Zotarelli M.F., Laurindo J.B., A convective multi-flash drying process for producing dehydrated crispy fruits. J. Food Eng., 2012, 108, 523-531.

[15] Chun Y.N., Kim S.C., Yoshikawa K., Pyrolysis gasification of dried sewage sludge in a combined screw and rotary kiln gasifier. Appl. Energ., 2011, 88, 1105-1112.

[16] Li Y., Lei Y., Zhang L.B., Peng J.H., Li C.L., Microwave drying characteristics and kinetics of ilmenite. T. Nonferr. Metal. Soc., 2011, 21, 202-207.

[17] Rattanadecho P., Makul N., Microwave-assisted drying: a review of the state-of-the-art. Dry. Technol., 2016, 34, 1-38.

[18] Jiang J., Dang L., Yuensin C., Tan H., Pan B., Wei H., Simulation of microwave thin layer drying process by a new theoretical model. Chem. Eng. Sci., 2017, 162, 69-76.

[19] Huang K.M., Cao X.J., Liu C., Liu C.J., Xu X.B., Measurement/ computation of effective permittivity of dilute solution in saponification reaction. IEEE T. Microw. Theory., 2003, 51, 2106-2111.

[20] Li Z.Y., Wang R.F., Kudra T., Uniformity Issue in Microwave Drying. Dry. Technol., 2011, 29, 652-660.

[21] Wang J., Hong T., Xie T., Yang F., Hu Y., Zhu H., Impact of filled materials on the heating uniformity and safety of microwave heating solid stack materials. Processes, 2018, 6, 220-233.

[22] Tran T., Nguyen H., Nguyen D., Nguyen T., Optimization of microwave-assisted extraction of essential oil from vietnamese basil (Ocimum basilicum L.) using response surface methodology. Processes, 2018, 6, 206-219.

[23] Guo Z.Y., Ju S.H., Lei T., Peng J.H., Zhang L.B., Jiang F., Optimization on drying of $\mathrm{CuCl}$ residue by hot-air using response surface methodology. In: Battle T.P. (Ed.), The Minerals, Metals \&
Materials Society (15-19 March 2015, Orlando, USA). Walt Disney World, Orlando, 2015, 73-80.

[24] Le T., Ju S., Lu L., Koppala S., Peng J., Microwave drying of $\mathrm{CuCl}$ residue from hydrometallurgical zinc recovery process. Dry. Technol., 2018, 37, 47-58.

[25] Lin G., Liu C., Zhang L., Hu T., Peng J., Li J., et al., High temperature dielectric properties of spent adsorbent with zinc sulfate by cavity perturbation technique. J. Hazard. Mater., 2017, 330, 36-45.

[26] Jiang Y., Liu B., Liu P., Peng J., Zhang L., Dielectric properties and oxidation roasting of molybdenite concentrate by using microwave energy at $2.45 \mathrm{GHz}$ frequency. Metall. Mater. Trans. B, 2017, 48, 3047-3057.

[27] Guo Z., Guo P., Su G., Zhai D., Cheng F., Li F., High-Temperature Permittivity and Microwave Pretreatment Characteristics of Nickel-Containing Sludge from Battery Production. Processes, 2019, 7, 257.

[28] Erbay Z., Icier F., A review of thin layer drying of foods: theory, modeling, and experimental results. Criti. Rev. Food Sci., 2010, 50, 441-464.

[29] Jayas D., Cenkowski S., Pabis S., Muir W., Review of thin-layer drying and wetting equations. Dry. Technol., 1991, 9, 551-588.

[30] Hii C.L., Law C.L., Cloke M., Modeling using a new thin layer drying model and product quality of cocoa. J. Food Eng., 2009, 90, 191-198.

[31] Suwannapum N., Rattanadecho P., Analysis of heat-mass transport and pressure buildup induced inside unsaturated porous media subjected to microwave energy using a single (te \r, 10\r,) mode cavity. Dry. Technol., 2011, 29, 1010-1024.

[32] Prat M., Recent advances in pore-scale models for drying of porous media. Chem. Eng. J., 2002, 86, 153-164.

[33] Pickles C.A., Microwave drying of nickeliferous limonitic laterite ores. Can. Metall. Quart., 2013, 44, 397-408.

[34] Song Z., Jing C., Yao L., Zhao X., Wang W., Mao Y., et al., Microwave drying performance of single-particle coal slime and energy consumption analyses. Fuel Process. Technol., 2016, 143, 69-78.

[35] Zhu J.F., Liu J.Z., Wu J.H., Cheng J., Zhou J.H., Cen K.F., Thin-layer drying characteristics and modeling of Ximeng lignite under microwave irradiation. Fuel Process. Technol., 2015, 130, 62-70.

[36] Soysal Y., Microwave drying characteristics of parsley. Biosyst. Eng., 2004, 89, 167-173. 